\title{
A POÉTICA DA PERFORMANCE E OS TERNOS DE REIS DE FLORIANÓPOLIS/SC
}

\section{THE POETIC OF PERFORMANCE AND THE TRADITIONAL SINGERS OF CHRISTMAS AT FLORIANOPOLIS CITY / BRAZIL}

Resumo: Este ensaio busca analisar as performances dos ternos de reis, uma expressão da cultura popular brasileira e neste caso mais específico, catarinense, sob a ótica da antropologia e do ritual elencadas nas teorias de Richard Schechner (2012) e de Turner apud Schechner (2012), bem como fazer uma ponte entre a poética (SUHAMY, 1988) e a arte performática das cantorias de natal, ano novo e dia de reis, cantadas pelos grupos de ternos de reis em Florianópolis, Santa Catarina, Brasil.

Palavras-chave: performance; ritual; poética; cultura popular; cantorias.

\begin{abstract}
This essay searches to analyze the Christmas Singer's performances, as an expression and experience of the popular culture in Brazil and most specific in Santa Catarina State. In this particular case the author has used the theoric approach about performance by Richard Schechner (2012) and also Victor Turner apud Schechner, (2012) and used too the theory about Poetic by Henry Suhamy (1988). The author means by that, explain the performatic acts, as poetic expressions of an ancient art, brought to south Brazil by the Portuguese people and which remains alive until nowadays at Florianopolis City, Santa Catarina, Brazil.
\end{abstract}

Keywords: performance; ritual; poetics; popular culture; chantings.

De acordo com Henry Suhamy, "podemos definir provisoriamente a Poética como designativa, ao mesmo tempo, da arte e da ciência da poesia." Segundo o mesmo autor, "sabemos que poesia e Poética derivam, histórica e semanticamente do grego poiêsis, criação. [...] Segue-se que etimologicamente poeta significa criador." (SUHAMY, 1988, p. 7) A poesia, portanto, seria antes de mais nada uma criação, uma forma de trazer ao mundo das palavras aquilo que de alguma maneira está vinculado à experiência humana. No caso dos

\footnotetext{
${ }^{1}$ Universidade Federal do Rio Grande do Sul, Porto Alegre, Brasil. Doutoranda em Literatura Portuguesa e Luso-Africanas (UFRGS) E-mail: liviajahn@gmail.com.
} 
Ternos de Reis, temos uma poesia popular que irá refletir através de cânticos religiosos, a perpetuação de uma série de crenças e valores sociais. São estes cânticos, advindos de textos sagrados que irão dar corpo e forma às performances dos Ternos de Reis. Assim, temos uma dupla poética inserida nestas manifestações culturais, poética aqui entendida como arte e ciência da poesia, como dito acima, e também como criação performática, foco deste ensaio. Portanto, nos Ternos de Reis, temos de um lado toda a tradição da poesia popular e do folclore, da versificação feita de fórmulas mnemônicas, de ritmo e métrica próprios, de uma gramática do improviso; e de outro lado, temos a expressão performática, o canto e a voz, o corpo e o gesto, os cantores e seu público. É essa expressão oral, performática e popular que iremos tratar neste artigo.

\section{A performance enquanto ritual}

Para falarmos de performance, vamos primeiramente definir o termo, que por si só é bastante variável e ambíguo em definições. Performance é todo ato ritualístico ou não, em que há um jogo entre público/ plateia/ audiência e o artista ou performer, ou seja, toda ação dada num determinado espaço/tempo em que público e artista são uma única unidade, focam numa mesma direção e estão juntos dentro da mesma realidade, seja ela fíccional ou não. Performance é assim, uma espécie de jogo, entre ator / artista e público/ audiência. Aproveitamos aqui, para incluir as palavras de Schechner sobre este assunto:

Performances são fazer-crer no jogo, por prazer. Ou como Victor Turner disse, no modo subjuntivo, o famoso 'como se'. Ou, como poderia ser na estética sânscrita, performances são lilas (jogo, brincadeira) e maya (ilusão). Mas a tradição sânscrita enfatiza: então tudo é vida, Lila e Maya. Performance é uma ilusão da ilusão, e como tal, deve ser considerada mais 'cheia de verdade', mais 'real' que uma experiência comum. Isso também foi a opinião de Aristóteles em sua Poética, na qual apresenta o paradigma de que o teatro não somente reflete a vida como a essencializa. [...] Porque performances são usualmente subjuntivas, liminares, perigosas, elas são com freqüência, duplamente cercadas por convenções e molduras: meios de fazerem os lugares, os participantes e os eventos de alguma maneira seguros. Nesses limites do fazer-crer, relativamente seguros, as ações podem ser levadas ao extremo, mesmo por prazer. (SCHECHNER, 2012, p.19-20).

No caso dos ternos de reis, as performances são eventos em que os músicos e cantores saem ao relento pela noite em busca do acolhimento de seus vizinhos e compadres para cantar 
nas casas destes, os cânticos religiosos em formas poéticas, do advento de Jesus Cristo, seu nascimento e a chegada dos três reis magos. Por ser uma performance praticada em datas específicas e em lugares determinados, ou seja, 25 de dezembro, 31 de dezembro e 6 de janeiro, marcando assim, a data maior do Cristianismo e também os solstício de verão / inverno, dependendo do continente, e por tratar-se de um evento cultural de bases religiosas e folclóricas, fomos levados a pensar nesta performance como sendo uma espécie de ritual. Ritual de passagem, de nascimento de uma nova era, de um novo ano, de um novo messias. Nascimento das esperanças da comunidade num futuro melhor, numa sociedade mais justa, e em tantas outras crenças e valores apregoadas pelo cristianismo. Como explicou Schechner, trata-se de uma ilusão cheia de verdade, posto que a convenção ritual, o funcionamento religioso torna os participantes mais seguros. Desta maneira, os Ternos de Reis marcam uma passagem no calendário social e religioso e por isso, suas performances podem ser tomadas como uma espécie de ritual religioso advindo do paganismo que foi absorvido pelo cristianismo e que se manteve vivo em Portugal e no sul do Brasil, onde houve forte influência portuguesa e açoriana. Trataremos nesse ensaio das manifestações registradas em trabalho de campo na cidade de Florianópolis. ${ }^{2}$ Mas o que é um ritual? De acordo com Schechner:

rituais são uma forma de as pessoas lembrarem. Rituais são memórias em ação, codificadas em ações. Rituais também ajudam pessoas a lidar com transições difíceis, relações ambivalentes, hierarquias e desejos que problematizam, excedem ou violam as normas da vida diária. [...] Ambos, ritual e jogo, levam as pessoas a uma "segunda realidade", separada da vida cotidiana. Esta realidade é onde elas podem se tornar outros que não seus eus diários. Quando temporariamente se transformam ou expressam um outro, elas performam ações diferentes do que fazem na vida diária. Por isso, ritual e jogo transformam pessoas, permanente ou temporariamente. Estes são chamados 'ritos de passagem' e alguns exemplos são: casamentos, iniciações, funerais. (SCHECHNER, 2012, p. 49-50)

Na medida em que cantores de Ternos de Reis são transformados temporariamente nos arautos da vinda de Cristo, eles se transportam para outra realidade, a realidade da religião, da

\footnotetext{
${ }^{2}$ Este ensaio discute assuntos que compõem a tese de Doutorado da autora, a ser concluída em março de 2015. Os relatos de Ternos de Reis aqui referidos foram realizados em trabalho de campo da pesquisadora nos meses de dezembro de 2011 e janeiro de 2012, na cidade de Florianópolis, capital do estado de Santa Catarina. A presença de colonos açorianos desde o século XVI é fundamental para a formação e para a história local, particularmente nos bairros Ribeirão da Ilha (que fica no extremo sul da ilha) e Palhoça (ao norte). Ambos caracterizados pela forte colonização açoriana e por serem vilas de pescadores. $\mathrm{O}$ ambiente provinciano de tais lugares permitiu que fosse preservada a memória das festas religiosas, em especial a Festa do Divino e a manifestação dos Ternos de Reis.
} 
fé, do rito de passagem que significou o nascimento de Jesus. Assim, de pescadores, jardineiros, zeladores de prédio, estes homens se transformam em vates e bardos, poetas e profetas, músicos e pregadores, que, possuídos de outra realidade, a realidade da fé cristã, vão aos lares anunciar a chegada de Deus, do Salvador. Desta maneira, as performances não são simples cantorias, como supõe, por exemplo, uma seresta. As performances de ternos são a visita de Nosso Senhor a determinados lares das vizinhanças, e são recebidos como sendo uma espécie de Vox Domini (a voz de Deus). Isso é tão real e tão palpável, que já houve quem doasse o pouco que tinha para os cantores de ternos por ver neles, uma expressão da força divina, como se o lar daquela pessoa tivesse sido escolhido por Deus, para receber os cantores. Isso exemplifica a dinâmica de ritual e jogo, que conduz a vida ordinária a uma "segunda realidade", levando os participantes a se tornarem outros que não os vividos no cotidiano. Foi esta a mensagem que me passou uma senhora a quem visitei e que me contou sua experiência religiosa desta maneira. Desse modo, os cantores são recebidos nas casas como verdadeiros enviados do Senhor, e tanto o público quanto os músicos, têm em conjunto uma experiência de comunhão religiosa, de pertencerem á mesma humanidade, de serem “irmãos". Essa experiência de "irmandade", de união transcendental, foi nomeada pelo antropólogo Victor Turner de communitas. De acordo com Schechner e citando Turner:

rituais são mais que estruturas e funções: eles podem também ser experiências poderosas que a vida tem a oferecer. Em um estado liminar, as pessoas estão livres das demandas da vida diária. Elas sentem o outro como um de seus camaradas e toda diferença pessoal e social é apagada. Pessoas são elevadas, arrastadas para fora de si. Turner chamou a liberação das pressões da vida ordinária de "antiestrutura" e a experiência de camaradagem ritual de communitas. [...]. A communitas espontânea é gerada através de certos procedimentos. Através de um limen ritual, dentro de um espaço / tempo sagrado. [...]. Esses no ritual, são todos tratados igualmente, reforçando um senso de 'nós estamos todos juntos'. Títulos formais são deixados de lado; algumas vezes até o primeiro nome é deixado de lado. Em vez disso, pessoas chamam cada um de 'irmã', 'irmão', 'camarada' ou algum outro termo genérico. (SCHECHNER, 2012, p. 68-69)

\section{A performance e seu caráter liminar, geradora de transportações e}

\section{transformações}

É interessante notar como um lugar ordinário, a casa, a rua, pode se transformar num ambiente sagrado através da performance. O ritual da cantoria une os artistas e as pessoas 
visitadas numa egrégora, numa espécie de irmandade transcendental, e os transporta para um espaço e um tempo fora do comum. Temos dessa maneira, a partir das músicas e dos versos cantados, a instauração de um tempo e de um espaço sagrados, liminar. Nesta espécie de ritual, ou de performance, como queira o nosso leitor, acontece o que o antropólogo e diretor teatral Richard Schechner chamou de transportações e transformações. Segundo este autor:

rituais liminares mudam permanentemente o que as pessoas são. Rituais liminóides efetuam uma mudança temporária - algumas vezes, nada mais do que uma breve experiência de communitas espontânea ou uma performance com várias horas de duração em um único papel. Ocorrem transportes. De um ponto de vista do espectador, uma entrada para a experiência é 'movida' ou 'tocada' e depois deixada onde ela aconteceu. Para os performers, a situação é mais complexa, pois ocorre uma 'longa jornada'. (SCHECHNER, 2012, p. 70).

Desta maneira, os Ternos de Reis seriam performances ou rituais "liminóides" onde ocorre uma mudança temporária nos cantores e espectadores, mas essa mudança não é definitiva. Uma mudança definitiva seria, por exemplo, a iniciação de um menino índio no mundo adulto. Depois do ritual, o menino é um homem da sua tribo e não mais uma criança. Ele está apto a caçar, pescar, casar e ter filhos. Ele mudou de status e de papel social na sua comunidade. Nos rituais dos Ternos de Reis existe uma mudança temporária de papéis: o pescador passa a ser cantor e mestre do terno, ele é poeta e músico ao mesmo tempo, ele é profeta e leva a boa nova da vinda de Cristo ás casas dos vizinhos. Por um curto espaço de tempo, o pescador é como um pregador, ele adquire um papel religioso, espiritual. Ele não é mais um simples homem do povo, mas ele é um homem que vem trazer uma verdade muito significativa a várias pessoas da sua comunidade. Ele é um profeta. Seus acompanhantes, outros músicos e cantores, também se investem do papel espiritual e desde que se encontram para cantar até o amanhecer do dia seguinte, vivem uma espécie de transformação da vida ordinária em momento sagrado, e de elevação de suas posições sociais muitas vezes desprestigiadas, para o status de profetas e pregadores da palavra de Deus. Desse modo é que são recebidos nas casas vizinhas, como arautos do Senhor, não como homens comuns, mas todos participantes de uma jornada singular, destacada da vida prosaica ainda que próxima, ou seja, um evento liminar.

As pessoas que os assistem também sofrem transformações, também adentram um momento sagrado, também se sentem especiais por terem sido escolhidas para ouvi-los. A visitação dos ternos é na realidade, uma honraria que a família daquela casa recebe. É uma distinção, e por isso, em geral, os donos da casa costumam receber os músicos e cantores com 
comes e bebes e lhes oferecer também dinheiro em paga pela visita. Segundo Schechner, este seria mais um ritual de transporte (onde as pessoas são transportadas para outra realidade) do que de transformação (onde ocorre uma mudança definitiva nas pessoas). Porém, isso não quer dizer que não haja transformações evidentes e temporárias nas pessoas envolvidas na performance. Geralmente, este tipo de acontecimento se dá de forma quase espontânea, unindo vizinhos, amigos, compadres. E todos os cantadores e mestres de ternos que entrevistamos foram enfáticos em dizer que seu canto é "inspirado" pelo momento, é absolutamente improvisado e espontâneo. Schechner também aborda esta realidade, mas para este estudioso da performance, o que ocorre é algo mais que improviso, é uma repetição de comportamentos, a que ele chama de "restauração" da performance. Em suas palavras, existem "performers - atores e músicos - que improvisam e para os quais cada instância é original. Mas, mesmo nesses casos, aplica-se a restauração do comportamento. Uma cuidadosa comparação de um número de instâncias poderia revelar faixas de comportamento repetido regularmente, bem como recorrendo a modelos de representação (regulagem de ritmo, tons de voz, gestos). São essas repetições que dão a cada performer o seu próprio estilo". (SCHECHNER, 2012, p. 72). Desta maneira, cada performer tem um repertório próprio de entonações, gestos, rimas, uma gramática do improviso, diria eu, parafraseando o diretor teatral. O comportamento "restaurado" se daria então pela repetição de fórmulas, de ritmos, de cantares, de gestos, repertório que o performer ou mestre de terno, já traria "pronto" de antemão.

Além do que já expusemos, seria interessante olhar para este "ritual de terno de reis" também como um "drama social". Turner chamou assim, os rituais que processavam aspectos políticos e/ou ideológicos numa dada sociedade. Qual seria o aspecto político ou ideológico, então desse "drama social"? A resposta que encontrei em minha pesquisa de campo é que os Ternos de Reis costumam dar-se em comunidades provincianas, de extrato bastante humilde, entre as classes ditas populares, termo esse bastante controverso, que carece de discussão que não caberia nos limites deste artigo. Por que surge esta iniciativa em comunidades de pescadores e/ou agricultores? Porque para estas pessoas o sentido de "comunidade", "bem comum", "vizinhança" e "compadrio" ainda é muito forte. Os elos que ligam vizinhos e compadres são vínculos extremamente estreitos, onde um ajuda o outro, onde todos se ajudam mutuamente, e todos se conhecem. As festas de Natal, Ano Novo e Dia de Reis é um motivo a mais para unir as famílias, os amigos, os vizinhos e compadres em torno de um sentimento de renovação e fraternidade, que se dá de forma alegre nos cânticos e versos dos Ternos de Reis. 
O estreitamento de laços, o sentido de comunhão e de pertencimento a uma família e a uma comunidade, seria uma das principais razões para a existência deste ritual, mas não a única. A união de forças entre vizinhos que vivem uma mesma condição socioeconômica bastante desfavorecida, explica muito do sentido dos ternos de reis. A outra explicação, subjacente, é a perpetuação do núcleo familiar como célula social, pois as visitas se dão em casas de famílias, são feitas para as famílias da comunidade e os ternos muitas vezes congregam famílias inteiras na cantoria (a Família Dias, de Blumenau, é um exemplo de Terno de Reis familiar que se expandiu até o ponto do espetáculo, matéria para a discussão a seguir). Assim, o "drama social e estético" praticado nos ternos de reis tem uma função de agregar a sociedade, agregar as famílias, manter o tecido social coeso e unido em prol do bem da comunidade a que pertence. Daí a sua perpetuação desde tempos imemoriais até os dias de hoje. Talvez para o leitor atento, tenham restado dúvidas sobre o que seja "drama social" e “drama estético", ou ambos juntos. Então, tomamos novamente as palavras do antropólogo e diretor teatral, para esclarecer:

Dramas estéticos criam tempos simbólicos, espaços e personagens; os caminhos da história são predeterminados pelo drama. Os dramas estéticos são ficções. Os dramas sociais têm mais variáveis, seus resultados são mais duvidosos e eles são como jogos. Os dramas sociais são 'reais', eles acontecem no 'aqui e agora'. Mas aspectos de dramas sociais, tais como dramas estéticos, são pré-organizados e ensaiados. (SCHECHNER, 2012, p. 80).

Podemos situar os Ternos de Reis entre os dramas sociais e estéticos. São dramas sociais porque têm um papel de coesão do tecido social, de união das famílias, de congregação dos vizinhos e compadres; por outro lado, é um drama estético porque lida com textos poéticos, com cantorias, música e encenação. A re-encenação do nascimento de Cristo e da visita dos três reis magos é uma forma estética de lidar com uma realidade histórica que, por vários motivos, também se tornou uma realidade religiosa e simbólica.

Entramos então, numa das partes mais interessantes da teoria de Schechner sobre performance e ritual: a díade eficácia - entretenimento. Para Schechner, existem diferenças entre o ritual e o teatro. Segundo o autor:

se alguém vai chamar uma performance específica de ritual ou teatro, isso depende em grande parte do contexto e função. Uma performance é chamada de um ou outro por causa do lugar onde ela é performada, por quem, em que circunstâncias e com que propósito. O propósito é o 
fator mais importante para determinar se uma apresentação é ritual ou não. Se o propósito da apresentação é efetuar uma mudança, então as outras qualidades abaixo do título 'eficácia' também vão estar presentes, e a performance é reconhecida como um ritual. Mas se a proposta da performance é principalmente dar prazer, ser mostrada, ser bela ou passar tempo, então a performance é um entretenimento. $\mathrm{O}$ fato é que nenhuma apresentação é eficácia pura ou entretenimento puro. (SCHECHNER, 2012, p. 81)

Um exemplo cabal do que este autor nos diz a respeito de eficácia e entretenimento é o da Família Dias, de Blumenau. ${ }^{3}$ Esta família, acostumada a performar Ternos de Reis há várias gerações, uniu-se e fez um espetáculo de Terno de Reis num teatro de Blumenau. Este espetáculo foi filmado e depois comercializado em DVD, forma como eu tomei contato com esta apresentação. Dizemos assim, então, que o espetáculo da Família Dias, passou do espectro de ritual para entretenimento, no momento em que é performado num teatro, voltado a um público variado, num espaço cênico, onde a própria visita do terno é encenada no palco. Aqui, podemos dizer com segurança, que o Terno de Reis da Família Dias, é puro entretenimento e que seu aspecto de ritual viu-se modificado por uma encenação absolutamente teatral e fictícia.

Já o Terno de Reis de Seu Luzair, de Seu Lili da Rabeca e de Seu Rivelino (todos eles entrevistados por esta pesquisadora) é absolutamente autêntico ${ }^{4}$, faz visita aos vizinhos e compadres nos bairros de Palhoça e Ribeirão da Ilha, compostos em sua maioria por moradores de baixa renda, com profissões variadas: pequenos comerciantes, pescadores, mecânicos, contínuos, empregados do comércio, domésticas, etc. O Terno de Reis conta com a ajuda dos amigos e é completamente absorvido pela comunidade circundante, o que o torna um ritual, e por sua vez, uma performance que se utiliza da eficácia, da transformação social e da transposição de um tempo e espaço ordinários para um tempo e espaço sagrados.

\footnotetext{
${ }^{3}$ Blumenau é uma cidade de colonização mista, alemã, italiana e açoriana. Fica situada ao norte de Santa Catarina e é conhecida pelas suas festas de origem germânica, a Oktoberfest. Nosso contato com a Família Dias, deu-se no dia 6 de janeiro de 2012, numa apresentação de vários grupos de Terno de Reis, em frente á Igreja Matriz de Florianópolis. Foi neste dia, que entrevistando o Sr. José Dias, fiquei sabendo que há mais de três gerações esta família se apresenta cantando Ternos de Reis, e as cantorias são parte importante da renda familiar. Nesta ocasião, comprei CDs e o DVD da Família Dias, este último, produzido no ano de 2010.

${ }^{4}$ Quanto aos entrevistados o Sr. Luzair é dono e mestre de um Terno de Reis e de um grupo de Boi de Mamão e vive em Palhoça, norte de Florianópolis. Entrevistei-o nos dias 27 de janeiro de 2012, 13 de fevereiro de 2012 e 17 de fevereiro de 2012. Registrei de seu Luzair, três performances: a cantoria do Terno de Reis, uma apresentação de Boi de Mamão, e uma entrevista onde ele também cantou alguns trechos de cantorias antigas. O Sr. Rivelino vive e canta no bairro Ribeirão da Ilha, ao sul de Florianópolis. Registrei sua performance de terno de reis em vídeo no dia 18 de janeiro de 2012, em sua casa. O Sr. Lili da Rabeca vive na praia dos Ingleses mas atua também no Ribeirão da Ilha, onde fez uma performance de Terno de Reis, filmada dia 15 de janeiro de 2012 .
} 
Temos assim, portanto, duas expressões da performance: a performance como ritual onde podemos justificar o termo "eficácia", já que ela transforma a comunidade onde é encenada; e a performance enquanto entretenimento que dá prazer e fruição estética á sua audiência, mas não tem o propósito de transformação social do ritual.

Quando um terno de reis deixa de atuar na comunidade para atuar no teatro, ele está se tornando um espetáculo, desvinculado das raízes mais antigas do ritual, ele se torna dessa maneira, mais um "show", um entretenimento para o público pagante. Existem, portanto, performances variadas mesmo dentro da tradição dos ternos de reis. Podemos concluir assim, como quer Schechner, que "as performances possuem várias finalidades, incluindo entretenimento, ritual, construção de uma comunidade e socialização. Essas funções podem ser resumidas como a tensão dinâmica entre a eficácia e o entretenimento." (SCHECHNER, 2012, p.83). Porém, no caso da Família Dias, temos um Terno de Reis já mais aperfeiçoado no sentido da cultura de massas, voltado mais para o entretenimento do que para a eficácia, ou seja, um grupo familiar dedicado ao espetáculo em si, e á difusão de suas músicas e vídeos, num processo claro de "comercialização" do artigo folclórico e cultural, que são as cantorias de Reis. Neste caso específico ocorre uma mudança sobre a qual Schechner novamente discorre:

A mudança de ritual para performance estética ocorre quando uma comunidade participativa se fragmenta, torna-se ocasional, com clientes pagantes. O movimento da performance estética para o ritual acontece quando um público formado por indivíduos se transforma em uma comunidade. As possibilidades de movimento em qualquer das direções estão presentes em todas as performances. (SCHECHNER, 2012, p. 83).

No caso específico da Família Dias, houve uma mudança de um comportamento ritualístico para uma performance de entretenimento, utilizando elementos característicos do folclore (como os cantores, os versos, as músicas) e agregando a eles elementos cênicos dignos de uma performance teatral: o espaço do teatro, as luzes, os microfones, o cenário, os figurinos, a gravação de DVD durante o espetáculo, a gravação de CD durante o espetáculo, os ingressos. Enfim, houve uma transposição de um ritual popular para um espetáculo comercial. Sob certo ponto de vista podemos dizer que se não houve uma transformação completa do ritual em espetáculo, houve pelo menos uma "corrupção" do ritual e seus significados mais profundos, e um esvaziamento do mundo simbólico. Desse modo, o espetáculo tornou um bem cultural em um bem de consumo, e sob este aspecto, apenas um momento de prazer e fruição, sem qualquer compromisso maior seja com o sentido de união 
entre as pessoas, seja com a necessidade de coesão social, seja com os valores apregoados há dois mil anos e que ainda se mantêm vivos na sociedade atual.

\section{Considerações finais}

Claro, há que se levar em consideração que as performances herdadas dos açorianos, há mais de dois séculos, sofreram mudanças significativas: os ternos deixaram de ser apenas compostos por três pessoas, e passaram a agregar mais cantores e músicos aos seus conjuntos; os ternos de reis também deixaram de ser exclusivamente masculinos para tornarem-se também conjuntos onde se a voz feminina não predomina, pelo menos participa ativamente, como na maioria dos ternos entrevistados por esta pesquisadora; e há casos em que a voz feminina é o elemento predominante e que os ternos são regidos por uma mulher, como também pude constatar em minha pesquisa de campo. Todas essas questões colocadas acima fazem parte das mudanças, das transformações ocorridas nas performances e na tradição da cantoria de reis.

Porém, por mais que haja transformações substanciais nos conjuntos em si, o ritual permanece o mesmo: os versos são cantados improvisadamente por um "mestre" que "puxa" os outros cantores para fazerem coro consigo. Assim, quem dá o ritmo e a toada é a voz do mestre, sempre dirigindo o coro e os músicos. Este coro sai pela noite afora, caminhando pelas redondezas até postar-se diante de uma das casas da vizinhança, e aí, defronte a casa escolhida, começa uma ladainha, um convite, a que o dono da casa acenda as luzes e receba os cantores. Tendo sido recebidos pelo dono da casa, os cantores adentram a sala e aí fazem louvores a família e cantam a chegada de Cristo e a vinda dos três Reis Magos. Representando os Reis, em sua cantoria, os cantores recebem da família uma mesa farta com café, aguardente, bolachas e quitutes variados. Há ocasiões também em que a família além da mesa abundante, oferece também dinheiro aos cantadores. Todas as ofertas são recebidas com louvores e cantoria. Nos Açores era costume os familiares bailarem ao som das cantorias (DIAS, 1981, p. 490). Em Florianópolis o baile não se firmou como tradição, mas as cantorias e louvores, sim. Depois dos agradecimentos finais, os cantores se retiram e partem para outra casa, e assim, sucessivamente até o amanhecer do dia seguinte.

Por toda a descrição que fizemos acima, podemos constatar o quanto de ritualística tem essas performances dos ternos de reis. Desta maneira, podemos afirmar de que se trata sem sombra de dúvida de uma forma de ritual de passagem, que marca o calendário cristão 
desde tempos remotos. Segundo Schechner os rituais têm diversas funções entre elas as seguintes:

O ritual também é uma forma de os povos se conectarem a um estado coletivo e, ao mesmo tempo, a um passado místico e construírem uma solidariedade social, para formar uma comunidade. Alguns rituais são liminares,existem entre ou fora da vida social cotidiana. Por causa de sua liminaridade, performances rituais podem produzir communitas, uma sensação de algo entre os participantes, maior ou fora de seu eu individual. (SCHECHNER, 2012, p. 88)

Dessa maneira, os ternos de reis constituem também uma "função social", qual seja a de agregar a vizinhança e as famílias, a de manter o tecido social coeso e com um sentido de pertencimento a uma dada comunidade. Dessa maneira, estas performances obedecem não só a uma tradição, que poderíamos situar dentro do âmbito do folclore, mas também a um funcionamento, a uma espécie de "azeitamento" das relações sociais, fazendo com que as pessoas pertencentes a um mesmo grupo não se dispersem, mas reiterem suas identidades enquanto sujeitos históricos e sociais.

Podemos inferir também, como conclusão final deste artigo, que há nestes rituais performáticos, toda uma poética: seja ela estritamente ligada à poesia dos versos cantados, suas rimas, aliterações e assonâncias, seja ela tida como uma espécie de "gramática do improviso", onde os cantadores e em especial o mestre cantor, usam de fórmulas mnemônicas e de rimas ancestrais e outras inventadas na hora para criar toda uma versificação e cantoria feitas para o momento presente. É este momento, o agora da canção, que dá aos ternos de reis toda a sua originalidade e também cria para eles, uma linguagem própria, uma "poética da voz", pois o verso se transforma em música, em canção, em comunhão com os amigos, parentes, vizinhos e até desconhecidos. O verso, poesia, se transforma em palavra falada, improvisada, cantada, e assim, perpassa o tempo, as vidas, o instante da performance e adentra a eternidade da arte, da poesia em forma de canção.

\section{Referências}

DIAS, Francisco José Tenente. Cantigas do Povo dos Açores. Angra do Heroísmo, Instituto Açoriano de Cultura, 1981.

SCHECHNER, Richard. Antropologia e Performance de Richard Schechner. Ligiéro, Zeca (org.). São Paulo: Hucitec, 2012. 
SUHAMY, Henry. A Poética. Rio de Janeiro: Jorge Zahar Editor, 1988. 